\title{
Better Closure Cost Estimates
}

\author{
A.H. Watson MWH Americas Inc., USA
}

\section{INTRODUCTION}

The most important element of sustainability in mining is that we stay in business. There are over 23000 abandoned mine openings from activity pre-1970, in the State of Colorado alone. Those early miners did not consider the cost associated with any activity external to the extraction of ore, and made no provision for retiring their mining assets when the lode played out. Approximately 3500 of those disturbances have been closed with Federal and State funds since the inactive mines program was implemented in the 1980s, and the State of Colorado is responsible for closing the rest of them eventually. There are currently approximately 6000 mines in Colorado permitted under the post-1970s mining law, requiring reclamation bonding. This is just one example of the many mining districts around the world where we have work to do.

\section{WHY WE NEED TO ESTIMATE ACCURATELY}

The rule of thumb was that the cash flow from disposing of the plant would cover the cost of mine closure. This cannot be taken for granted (Bartos, 2003). Miners' and financiers' initiatives to adopt universal best practices with respect to sustainable communities and the environment call us all to do better business. Accounting rules require us to fairly value and declare our mine closure liabilities on the balance sheet, even though they are perhaps a long way in the future. The continued move to standardize accounting practices internationally means that we're all reporting in a similar way.

Early estimates of our closure liabilities were poor. We were slow to acknowledge the externalities associated with our industry: psychologically, we're wired to hope for the best. But since the 1970s and at a greater pace this century, government and no-government organizations have become less forgiving of the environmental consequences of the valuable materials we produce. The mining community launched a bold initiative to take responsibility for our environmental performance, as manifested in the sustainability and social license to operate efforts. The potential hazard is making commitments now that we may not be able to keep when commodity prices come off their current highs. It is imperative that we make realistic estimates and adequately provide for the effort required to keep our promises.

\section{DIFFERENCE BETWEEN CAPITAL AND CLOSURE PROJECTS}

A major difference between capital and closure projects is the obligation to perform. A capital for-profit project may be cancelled at the owners' prerogative. Cancelling an environmental remediation project because the cost exceeds the financial provision is not acceptable.

A second, related, difference is the flexibility to manage the scope of a project. Typically when costs start to escalate, portions of the scope are renegotiated: an item is substituted or some capital expense is deferred for an increased operating cost in the future. This is what we refer to as value engineering and these decisions are justified by cost-benefit analyses. To a much lesser extent the same manipulations can be made in the closure scope; when one is being strictly regulated it is seldom possible to reduce scope elsewhere in the project in trade for the scope added in response to the change. The logical outcome is an escalation in scope with associated increase in cost.

\section{DEFINING THE SCOPE OF WORK}

The prescriptive requirements - environmental standards for water quality, habitat, post-closure land use, etc. are usually rather easily interpreted. There is now a minimum established in the form of the IMF or World Bank standards, if we seek financial backing from a major lender. A mining company might also self-impose certain requirements through a corporate charter, for example. We are discovering that it is often tougher to 
meet the standards being imposed than we had anticipated and, simultaneously, the standards are becoming more demanding. In estimating the cost of closure the greatest challenge we face is defining the scope.

The Project Management Institute in their guide to the project management body of knowledge refers to scope planning, scope definition and scope verification as distinct activities. Scope verification "is the process of formalizing acceptance of the project scope by stakeholders" (PMI, 2000). Our social license to operate is earned from our stakeholders and our scope has to address the concerns of the public we intend to be working with on the next project. We have got better at acknowledging and addressing the requirements of a broader audience, but the equator principles now ensure that we will find it harder to secure financing for projects without a proper analysis of stakeholders and their needs.

\section{$5 \quad$ RESIDUAL RISKS}

When provisioning for closure it is imperative that we make allowance for failure. For example, it is common to consider a 100-year return period for floods when sizing channels, but in the time frame of closure the design flow is likely to be exceeded. As this design parameter is the product of statistical analysis, each year that we gather additional data and each time a large storm event occurs, the value increases. There is also uncertainty around the outcome of closure measures. There are many case histories of closure measures that proved to be ineffectual or were destroyed by extreme events the like of which were not experienced during the operating life of the mine. The problem is that closure is for a very long time, and the possibility that additional work may be required, at additional cost, needs to be taken into account. Measures to address these possibilities can be added to the scope on a contingent basis.

\section{ACCURACY OF ESTIMATES}

Typically an engineering estimate is based on drawings, measurements and scaled or estimated unit rates. The most accurate and reliable estimate can be developed when all the elements of the work breakdown structure (WBS) and resource breakdown structure (RBS) have been defined with some certainty. Unfortunately the level of detail required for such a bottom-up estimate is not available until a major portion of the work has been designed and implemented. During the inception phase of the project the probability of occurrence of undesirable project events is very high, and early estimates, based of necessity on sketchy data, are inaccurate. Nonetheless, project managers use a variety of techniques to formulate project estimates as a basis for project comparison, selection of options and to secure project funding. These techniques include analogous, parametric and ratio estimating. These are easy to use, but their accuracy is not very high, particularly when a sizeable pool of industry-specific data is not available.

For construction and industrial projects, due to monitoring and reporting inaccuracies, estimates prepared near completion of a project are only accurate to within 3 percent or 4 percent. On the other end of the spectrum, when very little information is available the actual value of the project may range from 33 percent to 333 percent of the estimate ( $\operatorname{Rad}, 2002)$. Organizations typically refer to stages in the project lifecycle in terms of conceptual, pre-feasibility, feasibility and execution, and the American association of cost engineers (AACE international) uses the following progression of estimates: order of magnitude; conceptual; preliminary; definitive and control.

Organizations usually establish target levels of accuracy, sometimes better than plus or minus 35 percent even for "order of magnitude" estimates. However the accuracy of the estimate, regardless of what it is called, is determined by the nature and accuracy of the historical data. And cost estimating methods and tools that consider risks and variability in cost estimates, such as the use of range estimating and parametric estimating techniques, are not yet widely adopted by estimators and contractors (Akintola and Fitzgerald, 2000). In light of the paucity of experience with mine closure projects, it is no wonder that we are often not as accurate as we'd like to be.

\section{RANGE ANALYSES}

Our early estimates of the cost of closure, based on incomplete scientific investigations and conceptual engineering, are probably not within the targeted range of accuracy. But shareholders get tired of us repeatedly restating our worth and accounting rules require the determination of the most likely cost. Using 
statistical methods, we can estimate the most likely cost, even when we cannot claim to have achieved the target precision or level of accuracy, and we can gain an appreciation for the possible range of outcomes. This is a more mature approach, as it acknowledges the imprecision in the project estimate due to the lack of information, and declares the exposure of the owners should the outcome not be as favourable as we hope. Deterministic (single number) estimates cannot do that.

Portions of an estimate of closure costs in 2000 based on a scrap steel credit of $\$ 45$ per ton would be significantly overstated by 2005 when scrap steel fetched $\$ 250$ per ton. On the other hand, other portions of that same estimate would have been understated considerably given an almost threefold increase in the price of fuel and the scarcity of tyres. And these ranges are attributable only to price: when one considers that the results of long-term environmental studies or permit negotiations often require additions to the scope of work, it becomes clear that a wide range of outcomes is possible.

Consider the example of an estimate of the cost of soil remediation upon closure of a refinery. Based on similar work at another refinery and operator knowledge, we might estimate the extent and depth of soil to be removed or amended and the unit price for that work. We might measure the quantities carefully and get quotes from a hauler, a remediation contractor and the landfill to make our estimate more precise. But using that number in our budget is not the responsible thing to do until we have investigated the impact of potential changes. When that landfill is full before we close the operation and the next nearest repository is twice as far away, the haulage cost doubles. When the definitive soil investigation determines that the impacted soil extends below the foundations because of a spill that went unreported many years ago the actual quantity might more than double. When we start to consider the potential for scope creep in this manner, it very quickly becomes evident that the scope of work for closure is seldom precisely defined until late in the project. Inferring that the cost estimate is more accurate than our definition of the scope is precisely why we have been so wrong in the past.

Range analysis considers possible price and quantity fluctuations in each of the major work items. This can still be done at a high level when detailed information is not available. Using the example above again, we might declare that we hope to realize a 20 percent savings over the past project unit rates because we will be more efficient. But when we consider the potentially longer haul to the landfill and the extra quantity we might have to move, we have to admit that we might be doing more than double the work. Declaring the range is far more appropriate than saying that out estimate is "order of magnitude" and therefore has an accuracy of plus or minus 35 percent.

There are a number of techniques appropriate for this sort of exercise, including betting techniques and teamwork. It is best to work from best and worst cases towards the most likely case, rather than getting grounded in the deterministic estimate and not exploring the full range of possibilities. A detailed discussion of these techniques is not appropriate here, but it is important to note that precision is no indicator of accuracy. Reliable estimates of likely closure costs can be derived through probabilistic techniques, whereas additional work to improve the precision of a deterministic estimate does not always yield the implied improvement in accuracy.

\section{REPORTING AND ANALYSIS OF THE RESULTS}

The ranges, once declared, can be used in statistical analyses such as Monte-Carlo simulations of the project, or a suite of projects when an owner wishes to value the entire portfolio. Such a probabilistic simulation takes account of the independence of the various events: it is unlikely that we will pay the highest price and move the highest quantity for every work item. The result of such a simulation might be presented graphically in a bell curve as illustrated in Figure 1. 


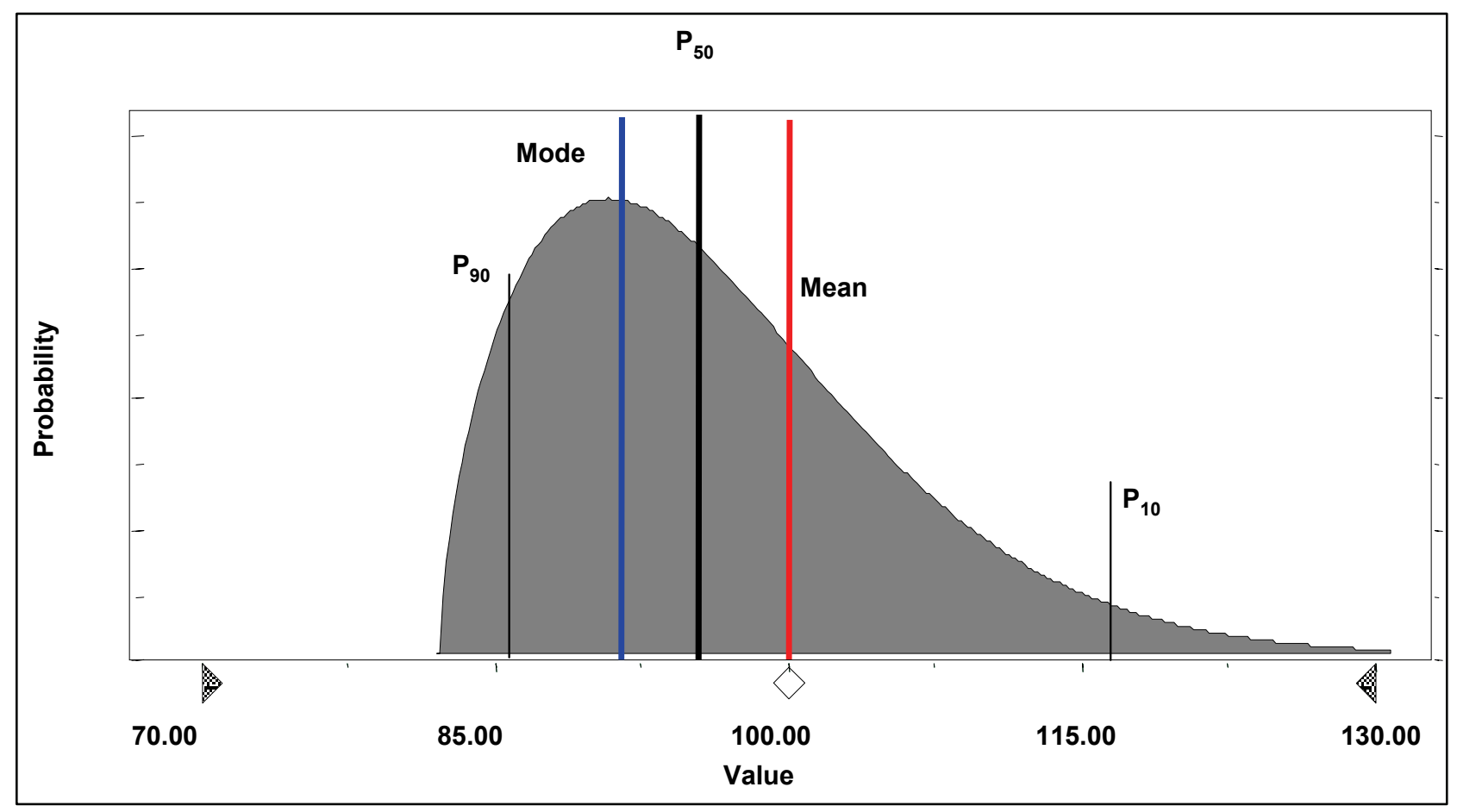

\section{Figure 1 Results of probabilistic example with asymmetrical distribution}

For the purposes of reporting closure liabilities, the most commonly reported value is the mean, even though when the probability is skewed, as illustrated above, this value may be greater than the 50-percentile and most probable (mode) values. For construction projects when the scope is well defined, the contingency is often defined as the difference between the 50-percentile value and the deterministic estimate (Lorance and Wendling, 1999).

Two pieces of information that are revealed by the probabilistic estimate are not commonly derived from a deterministic cost estimate. The first is an indication of what the worst and best possible outcomes might be. While for accounting purposes the mean value is appropriate, for an assessment of business risk the owner may wish to know what the gross exposure might be.

The second is an indication of the sensitivity of an estimate to individual items. This is evident when the range analysis is itemized, as illustrated in the tornado plot in Figure 2. The items with the greatest variability or largest potential impact on cost are easily identified and can be evaluated further, perhaps by breaking them down into smaller components or subjecting them to further analysis.

Together, these pieces of information provide valuable guidance to companies wishing to reduce their risk, indicating where risk mitigation efforts are best spent, and perhaps where a change in operating practice can reduce the liability at closure. 


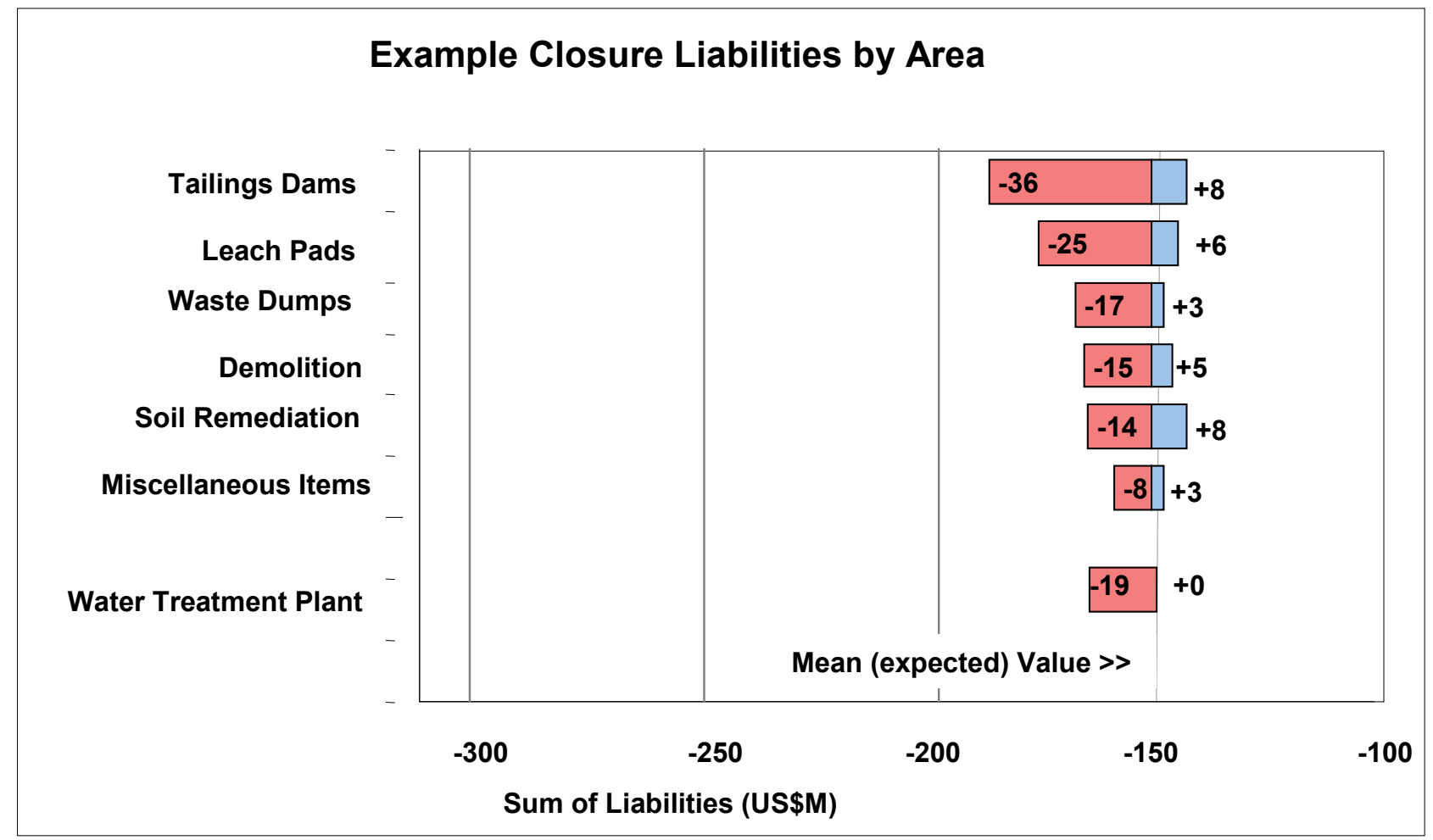

\section{Figure 2 Example tornado plot}

\section{CONCLUSIONS}

Single number estimates give no indication of how wrong they might be, and the confidence implied by the target level of accuracy has often proved unwarranted. It is better to be approximately correct than precisely wrong. Accounting rules require a fair valuation of the cost of retiring assets, and when closure is a long way away it is appropriate to declare the uncertainty surrounding the scope and future prices. Probabilistic analysis using risk management techniques provides a reliable method of doing this.

\section{REFERENCES}

Anonymous (2006) Mined land reclamation in Colorado: an overview. State of Colorado division of minerals and energy.

Bartos, P. (2003) Quoted in Hard Rock Miner's Handbook Rules of Thumb, Edition 3. Mackintosh Engineering, rule 7.18 .

PMI (2000) Project Management Body of Knowledge (PMBOK) 3rd Edition, Project Management Institute, Chapter 5.

Rad, P. (2002) Project Estimating and Cost Management, Management Concepts, Vienna (USA), pp. 43-66.

Akintola, A. and Fitzgerald, E. (2000) A survey of current cost estimating practices in the UK, Construction Management \& Economics, 2000, Vol. 18, Issue 2, Taylor and Francis, London, pp. 161-172.

Lorance, R. and Wendling, R. (1999) Basic Techniques for Analyzing and Presentation of Cost Risk Analysis, Crystal Ball, Denver. 